\title{
Comparison of maternal and perinatal outcome among patients with gestational diabetes treated with either metformin or insulin - an observational prospective cohort study
}

\author{
Jacob K.J' ${ }^{1}$ Mary Grace N.C ${ }^{2}$, Saleema ${ }^{3}$, Safina $F^{4}$ \\ ${ }^{1}$ Dr K J Jacob, Professor, Department of Obstetrics \& Gynecology, ${ }^{2}$ Dr Mary Grace N C, Associate Professor, Department of \\ Medicine, ${ }^{3}$ Dr Saleema Paduppingal, Junior Resident, Department of Obstetrics \& Gynecology, ${ }^{4}$ Dr Safna Farsana A.V, all \\ authors are affiliated with Government Medical College, Thrissur, Kerala, India.
}

Address for Correspondence: Dr Mary Grace N C, Email: Grace Jacob, email: marygracejacob65@gmail.com

\begin{abstract}
Introduction: Insulin therapy is the current gold standard in the treatment of gestational diabetes. Safe and effective oral therapy would be more acceptable to the pregnant population. We did this study to compare the maternal and fetal outcomes among patients treated with insulin and metformin in gestational diabetes. Materials and Methods: We did an observational prospective cohort study on 123 consecutive patients diagnosed to have gestational diabetes. Patients included in the study were followed up for the rest of the antenatal period, during labour and for 6 weeks after delivery for maternal and perinatal outcomes. Results: There was no significant difference between the two groups in respect to all the maternal and perinatal outcomes studied. Among the 61 patients in the metformin group $55(90 \%)$ attained glycemic target with metformin alone while $6(10 \%)$ had to be given insulin along with metformin. Conclusion: Metformin appears to be an effective treatment for gestational diabetes. Metformin is more acceptable to women due to its ease of administration and lower cost as compared to insulin. A drawback which is observed with the use of metformin is the inability of metformin therapy alone to achieve good glycemic control and thereby leading to adverse consequences in the fetus.
\end{abstract}

Keywords: Gestational diabetes, Insulin, Metformin

\section{Introduction}

The prevalence of type 2 diabetes mellitus in India is on the rise and the number of women with gestational diabetes is also following the same trend. Insulin therapy is the current gold standard in the treatment of gestational diabetes [1]. The drawbacks of insulin include among others, difficulty in motivating the patients to take insulin, weight gain, risk of hypoglycaemia, practical difficulties like storage and multiple injections.

These difficulties are more among people of lower socioeconomic status. Safe and effective oral therapy would be more acceptable to the pregnant population. Oral hypoglycaemic agents were discouraged in pregnancy, mainly fearing terratogenicity. Recently it has been shown that oral agents like metformin, glibenclamide and acarbose could be safely used in pregnant patients with diabetes [2]. But the use of oral agents is not universally accepted. MIG trial studied the use of metformin in the treatment of gestational diabetes

Manuscript received: $5^{\text {th }}$ March 2017

Reviewed: $16^{\text {th }}$ March 2017

Author Corrected: $24^{\text {th }}$ March 2017

Accepted for Publication: 31 $1^{\text {st }}$ March 2017
[3]. We did this study to compare the maternal and fetal outcomes among patients treated with insulin and metformin in gestational diabetes.

\section{Materials and Methods}

Study design- We did an observational prospective cohort study.

Participants- The study population included 123 consecutive patients diagnosed to have gestational diabetes.

Setting- The study was done in the department of obstetrics and gynecology of Government Medical College Thrissur, tertiary care centre in the central part of Kerala.

Exclusion criteria- Those patients who were diagnosed with diabetes prior to pregnancy and those with fasting plasma glucose of $>126 \mathrm{mg} \%$ were excluded from the study. 
Inclusion criteria- All patients attending the antenatal clinic were screened for diabetes with fasting blood sugar. Those who had fasting blood glucose 92 - $125 \mathrm{mg} \%$ were considered to have gestational diabetes mellitus (GDM) [4] and were included in the study.

For those pregnant ladies who had fasting plasma glucose of $<92 \mathrm{mg} \%$, oral glucose tolerance test was done at 24 28 weeks gestation as per International Association of Diabetes and Pregnancy Study Group guidelines. If the fasting plasma glucose after $75 \mathrm{~g}$ of glucose was $>92$ $\mathrm{mg} \%$ or the 1 hour value was $>180 \mathrm{mg} \%$ or the 2 hour value was $>153 \%$ they were diagnosed to have GDM. Those patients diagnosed with GDM who achieved glycemic targets (pre-prandial capillary glucose $<95$ $\mathrm{mg} \%, 1$ hour post prandial $<140 \mathrm{mg} \%$ and 2 hour $<120$ $\mathrm{mg} \%$ ) by life style modifications -medical nutrition therapy and exercise were excluded from the study. If glycemic target is not achieved within 2 weeks, treatment was started with metformin or insulin. The two groups were comparable regarding their baseline characteristics like age, socioeconomic status, body mass index, past obstetric history and family history of gestational diabetes. Patients included in the study were followed up

\section{Original Research Article}

for the rest of the antenatal period, during labour and for 6 weeks after delivery for maternal and perinatal outcomes with respect to the following parameters. Ante partum parameters included threatened abortion, infections, hypertension, polyhydramnios, preterm labour, ketoacidosis, adequacy of blood sugar control, preterm premature rupture of membrane, premature rupture of membrane. Intrapartum parameters which were studied included type of delivery, genital tract injury, and shoulder dystocia. Post partum parameters were postpartum haemorrhage and post partum infections. The perinatal parameters which were analysed included congenital anomalies, prematurity, macrosomia, perinatal mortality, neonatal hypoglycaemia, hypocalcaemia, hyperbilirubinemia respiratory distress, APGAR score at birth, neonatal ICU admission, and neonatal death. Statistical methods. Statistical analysis was done using SPSS 16 soft ware. Quantitative data were expressed as mean \pm standard deviation. Qualitative data was expressed as percentages. The statistical tests used included chi square test. Chi square test was applied to find out the significance of association. $P$ value of less than 0.05 was taken as significant.

\section{Results}

Table-1: Showing the baseline characteristics of the patients in the two groups.

\begin{tabular}{|c|c|c|c|}
\hline Characteristic & $\begin{array}{c}\text { Metformin } \\
\text { n }(\%)\end{array}$ & $\begin{array}{c}\text { Insulin } \\
\text { n (\%) }\end{array}$ & $95 \%$ CI \\
\hline $\begin{array}{c}\text { Age } \\
<19 \text { years } \\
\text { 20-24years } \\
25-29 \text { years } \\
\text { 30-34years } \\
\text { >35years } \\
\text { Total } \\
\end{array}$ & $\begin{array}{c}\text { nil } \\
5(8) \\
30(49) \\
26(43) \\
\text { nil } \\
61 \\
\end{array}$ & $\begin{array}{c}\text { nil } \\
4(7) \\
29(47) \\
28(45) \\
1(2) \\
62 \\
\end{array}$ & \\
\hline $\begin{array}{c}\text { Parity } \\
\text { Primi } \\
\text { Multipara } \\
\text { Grand multipara } \\
\end{array}$ & $\begin{array}{c}30(49.2) \\
30(49.2) \\
1(.8) \\
\end{array}$ & $\begin{array}{c}25(40) \\
36(58) \\
1(1) \\
\end{array}$ & \\
\hline $\begin{array}{c}\text { Socioeconomic status } \\
\text { APL } \\
\text { BPL } \\
\end{array}$ & $\begin{array}{l}11(18) \\
50(82) \\
\end{array}$ & $\begin{array}{l}14(23) \\
48(77) \\
\end{array}$ & $0.3-1.8$ \\
\hline $\begin{array}{c}\text { BMI } \\
\text { Normal(19-24) } \\
\text { Overweight }(25-29) \\
\text { Obese }(>30) \\
\end{array}$ & $\begin{array}{c}24(40) \\
30(50) \\
6(10) \\
\end{array}$ & $\begin{array}{c}21(34) \\
36(58) \\
5(8) \\
\end{array}$ & $0.4-1.6$ \\
\hline $\begin{array}{c}\text { Previous birth weight } \\
>4.5 \mathrm{~kg} \\
3.5-4.4 \mathrm{~kg} \\
2.5-3.4 \mathrm{~kg} \\
<2.5 \mathrm{~kg} \\
\end{array}$ & $\begin{array}{c}2(3) \\
16(26) \\
4(7) \\
1(2) \\
\end{array}$ & $\begin{array}{c}4(7) \\
17(27) \\
3(5) \\
1(2) \\
\end{array}$ & $0.08-3$ \\
\hline $\begin{array}{c}\text { Past history of GDM } \\
\text { Past history of HT } \\
\text { History-anomalous baby } \\
\text { Family history of GDM }\end{array}$ & $\begin{array}{c}7(44 \%) \\
5(39 \%) \\
1(25 \%) \\
28(45 \%) \\
\end{array}$ & $\begin{array}{c}9(56 \%) \\
8(61 \%) \\
3(75 \%) \\
34(55 \%) \\
\end{array}$ & $\begin{array}{c}0.3-2.1 \\
0.2-2 \\
0.03-3.2 \\
0.3-1.4 \\
\end{array}$ \\
\hline
\end{tabular}


There were 61 patients in the metformin group and 62 patients in the insulin group. Majority of the patients in both the groups belonged to the age group of 25-34 years. The two groups were similar with regards their base line characteristics.

Table-2: Comparing the maternal outcome in the metformin and insulin groups.

\begin{tabular}{|c|c|c|c|}
\hline Parameter & Metformin n (\%) & Insulin n (\%) & 95\% CI \\
\hline History of threatened abortion & $5(56 \%)$ & $4(44 \%)$ & $0.3-5$ \\
\hline Infections & $20(50 \%)$ & $20(50 \%)$ & $0.5-2.1$ \\
\hline Hypertension & & & $0.2-2.3$ \\
Gestational hypertension & $5(42 \%)$ & $7(58 \%)$ & $0.4-6$ \\
Mild preeclampsia & $6(60 \%)$ & $4(40 \%)$ & $0.3-6.4$ \\
\hline Severe preeclampsia & $4(57 \%)$ & $3(43 \%)$ & $0.5-4.3$ \\
\hline Preterm PROM & $8(57 \%)$ & $6(43 \%)$ & $0.4-3$ \\
\hline PROM & $8(47 \%)$ & $9(53 \%)$ & $0.1-2.6$ \\
\hline Polyhydramnios & $3(38 \%)$ & $5(62 \%)$ & $0.5-3.7$ \\
\hline Preterm labour & $10(56 \%)$ & $8(44 \%)$ & $0.38-0.57$ \\
\hline Ketoacidosis & nil & nil & $0.3-1.9$ \\
\hline Blood sugar control & $55(90 \%)$ & $62(100 \%)$ & $0.5-2.2$ \\
\hline Abdominal circumference & $9(43 \%)$ & $12(57 \%)$ & $0.5-2.3$ \\
\hline Induced labour & $34(49 \%)$ & $36(51 \%)$ & $0.04-5.6$ \\
\hline Assisted delivery & $24(51 \%)$ & $23(49 \%)$ & $0.06-16$ \\
\hline Genital tract injury & $1(33 \%)$ & $2(67 \%)$ & $0.2-2.9$ \\
\hline Shoulder dystocia & $1(50 \%)$ & $1(50 \%)$ & $0.3-6.4$ \\
\hline Postpartum haemorrhage & $5(46 \%)$ & $6(54 \%)$ & $0.2-2.4$ \\
\hline Postpartum infection & $4(57 \%)$ & $3(43 \%)$ & $10(67 \%)$ \\
\hline GTT after 6 weeks & $5(33 \%)$ & & \\
\hline
\end{tabular}

Of the 40(33\%) patients who had infection in the antenatal period the commonest was vulvovaginitis in $19(15 \%)$ followed by urinary tract infection $13(11 \%)$, respiratory infection $8(7 \%) .12(10 \%)$ of the study population had gestational hypertension, $10(8 \%)$ had mild preeclampsia, $7(6 \%)$ had severe preeclampsia.

There was no significant difference between the two groups in respect to all the maternal and perinatal outcomes studied. Among the 61 patients in the metformin group $55(90 \%)$ attained glycemic target with metformin alone while $6(10 \%)$ had to be given insulin along with metformin. All the 62 patients who were started on insulin achieved glycemic target. GTT was done in 66 patients at 6 weeks post partum and was abnormal in 15(23\%)

Table-3: Showing the neonatal outcome in the metformin and insulin groups.

\begin{tabular}{|c|c|c|c|}
\hline Parameter & Metformin n(\%) & Insulin n(\%) & 95\%CI \\
\hline Congenital anomalies & $4(40 \%)$ & $6(60 \%)$ & $0.18-2.4$ \\
\hline Prematurity & $10(56 \%)$ & $8(44 \%)$ & $0.5-3.6$ \\
\hline Macrosomia & $4(40 \%)$ & $6(60 \%)$ & $0.18-2.4$ \\
\hline IUD & nil & nil & $0.3-1.7$ \\
\hline Neonatal hypoglycaemia & $10(42 \%)$ & $14(58 \%)$ & $0.02-2.2$ \\
\hline Hypocalcaemia & $1(20 \%)$ & $4(80 \%)$ & $0.08-2.8$ \\
\hline Respiratory distress & $2(33 \%)$ & $4(67 \%)$ & $0.3-1.8$ \\
\hline Hyperbilirubinemia & $11(44 \%)$ & $14(56 \%)$ & $0.06-16$ \\
\hline Birth trauma & $1(50 \%)$ & $1(50 \%)$ & $0.18-2.4$ \\
\hline Polycythemia & $4(40 \%)$ & $6(60 \%)$ & $0.06-16$ \\
\hline APGAR $<7$ at 5 minutes & $1(50 \%)$ & $1(50 \%)$ & $0.5-2.1$ \\
\hline NICU admission & $22(44 \%)$ & $22(44 \%)$ & \\
\hline
\end{tabular}

Congenital anomalies were seen in 10(8\%) which include one each of ventricular septal defect and meningomyelocele and 2 each of hydronephrosis, cleft lip, preauricular skin tag and congenital talipes equino varus. 


\section{Discussion}

Diabetes mellitus is one of the most important medical problems encountered in pregnancy. Gestational Diabetes Mellitus (GDM) is characterised by glucose intolerance with onset or first recognition in pregnancy [5]. Pregnancy is associated with a state of insulin resistance because of the effect of placental hormones. In normal pregnancy this state of insulin resistance is overcome by pancreatic beta cell hyperplasia and increased insulin levels. GDM results when the beta cells are unable to overcome this insulin resistance [6]. In India GDM has been estimated to affect nearly 5 million women. GDM is associated with adverse outcomes for both mother and child. There is increased risk for macrosomia and other complications in the fetus. A person with GDM is more likely to develop diabetes in later life. Treatment of GDM has been shown to reduce the adverse events. [7].

Nearly $80 \%$ of the patients with GDM can be managed with life style modification alone [8]. The pregnant women with higher blood sugar levels will need pharmacological interventions.Insulin is the drug of choice for the treatment of GDM. According to a recent study from India[9] insulin was used by $50.4 \%$ of the clinicians resorted to insulin in GDM, which was not controlled by life style modifications.Among the oral hypoglycaemic agents Metformin was used by the majority (53.8\%) [8]. Metformin which is a category B drug in pregnancy is now considered an easier alternative to insulin in the management of gestational diabetes mellitus [3]. There are randomised controlled trials which show that there are no differences in the maternal and neonatal outcomes with the use of metformin and insulin $[10,11]$. At the same time there are also observational studies which show increased risk of pre eclampsia and worse perinatal outcome with the use of metformin $[12,13]$.

Some studies also have shown added advantages with metformin therapy like lesser maternal weight gain $[14,15]$ and lesser fetal macrosomia and neonatal hypoglycaemia [15]. We have observed in this study that there are no significant differences in both the maternal and neonatal outcomes with the use of metformin or insulin. But the main drawback of metformin appears to be the inability to achieve good glycemic control when used as monotherapy and the subsequent inadvertent risk of hyperglycemia to the fetus [1]. In the MIG trial $46.3 \%$ of the patients in the metformin group needed additional insulin to maintain glycemic target [3]. Our observation is that only $10 \%$ of the patients who were started on metformin monotherapy had to be given additional insulin in order to achieve glycemic target.

\section{Conclusion}

Metformin appears to be an effective treatment for gestational diabetes. Metformin is more acceptable to women due to its ease of administration and lower cost as compared to insulin. A drawback which is observed with the use of metformin is the inability of metformin therapy alone to achieve good glycemic control and thereby leading to adverse consequences in the fetus.

Funding: Nil, Conflict of interest: Nil

Permission from IRB: Yes

\section{References}

1. Awadhesh Kumar Singh, Ritu Singh. Metformin in gestational diabetes: An emerging contender.Indian Journal of Endocrinology and Metabolism 2015;19(2) : 236-244 DOI: 10.4103/2230-8210.149317

2. Nagandla Kavitha, Somsubhra De, Sachchithanantham Kanagasabai. Oral Hypoglycemic Agents in pregnancy: An Update. J Obstet Gynaecol India. 2013; 63(2): 8287.doi: 10.1007/s13224-012-0312-z.

3. Rowan JA, Hague WM, Gao W, Battin MR, Moore MP; MiG Trial Investigators. Metformin versus insulin for the treatment of gestational diabetes. $\mathrm{N}$ Engl J Med. 2008 May 8;358(19):2003-15. doi: 10.1056/NEJMoa 0707193 .

4. International Association of Diabetes and Pregnancy Study Groups Consensus Panel.International Association of Diabetes and Pregnancy Study Groups Recommendations on the Diagnosis and Classification of Hyperglycemia in Pregnancy. Diabetes Care 2010; 33(3): 676-682. http://dx.doi.org/10. 2337/dc 09-1848.

5. Garrison A. Screening, diagnosis, and management of gestational diabetes mellitus. Am Fam Physician. 2015 Apr 1;91(7):460-7.

6. Butte NF. Carbohydrate and lipid metabolism in pregnancy: normal compared with gestational diabetes mellitus. Am J Clin Nutr. 2000;71(5 suppl):1256S-1261S.

7. Crowther CA, Hiller JE, Moss JR, McPhee AJ, Jeffries WS, Robinson JS; Australian Carbohydrate Intolerance Study in Pregnant Women (ACHOIS) Trial Group. Effect of treatment of gestational diabetes mellitus on pregnancy outcomes. N Engl J Med. 2005 Jun 16;352(24):2477-86. Epub 2005 Jun 12.

8. Standards of Medical Care in Diabetes- 2017 Diabetes Care 2017;40(Suppl. 1):S1-S2 | DOI: 10.2337/dc17-S001. 
Original Research Article

9. Mohan V, Mahalakshmi MM, Bhavadharini B, Maheswari K, Kalaiyarasi G, Anjana RM, Uma R, Usha S, Deepa M, Unnikrishnan R, Pastakia SD, Malanda B, Belton A, Kayal A. Comparison of screening for gestational diabetes mellitus by oral glucose tolerance tests done in the non-fasting (random) and fasting states. Acta Diabetol. 2014 Dec;51(6):1007-13. doi: 10.1007/s 00592-014-0660-5. Epub 2014 Oct 15.

10. Hague WM, Davoren PM, Oliver J, Rowan J. Contraindications to use of metformin. Metformin may be useful in gestational diabetes. BMJ. 2003 Apr 5;326 (7392):762; author reply 762 .

11. Moore LE, Briery CM, Clokey D, Martin RW, Williford NJ, Bofill JA, Morrison JC. Metformin and insulin in the management of gestational diabetes mellitus: preliminary results of a comparison. J Reprod Med. 2007 Nov;52(11):1011-5.
12. Hellmuth E, Damm P, Mølsted-Pedersen L. Oral hypoglycaemic agents in 118 diabetic pregnancies. Diabet Med. 2000 Jul;17(7):507-11.

13. Ekpebegh CO, Coetzee EJ, van der Merwe L, Levitt NS. A 10-year retrospective analysis of pregnancy outcome in pregestational type 2 diabetes: Comparison of insulin and oral glucose-lowering agents. Diabet Med 2007; 24:253-8.

14. Niromanesh S, Alavi A, Sharbaf FR, Amjadi N, Moosavi S, Akbari S. Metformin compared with insulin in the management of gestational diabetes mellitus: a randomized clinical trial. Diabetes Res Clin Pract. 2012 Dec; 98(3):422-9. doi: 10.1016/j.diabres.2012.09.031. Epub 2012 Oct 12.

15. Hassan JA, Karim N, Sheikh Z. Metformin prevents macrosomia and neonatal morbidity in gestational diabetes. Pak J Med Sci 2012;28:384-9.

\section{How to cite this article?}

Jacob K.J, Mary Grace N.C, Saleema, Safina F. Comparison of maternal and perinatal outcome among patients with gestational diabetes treated with either metformin or insulin - an observational prospective cohort study. Obs Rev:J obstet Gynecol 2017;3(1):1-5.doi: 10.17511/joog.2017.i01.01. 